Article

\title{
Some Root Level Modifications in Interval Valued Fuzzy Graphs and Their Generalizations Including Neutrosophic Graphs
}

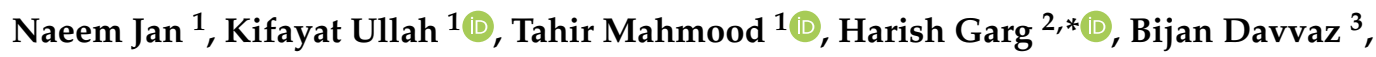 \\ Arsham Borumand Saeid ${ }^{4}$ and Said Broumi ${ }^{5}$ \\ 1 Department of Mathematics and Statistics, International Islamic University Islamabad Pakistan, Islamabad \\ Capital Territory 44000, Pakistan; naeem.phdma73@iiu.edu.pk (N.J.); kifayat.phdma72@iiu.edu.pk (K.U.); \\ tahirbakhat@iiu.edu.pk (T.M.) \\ 2 School of Mathematics, Thapar Institute of Engineering \& Technology, Deemed University, \\ Patiala 147004, Punjab, India \\ 3 Department of Mathematics, Yazd University, Yazd 89195-741, Iran; davvaz@yazd.ac.ir \\ 4 Department of Pure Mathematics, Faculty of Mathematics and Computer, Shahid Bahonar University of \\ Kerman, Kerman 7616913439, Iran; a_b_saeid@yahoo.com \\ 5 Laboratory of Information Processing, University Hassan II, Casablanca 20000, Morocco; \\ broumisaid78@gmail.com \\ * Correspondence: harishg58iitr@gmail.com; Tel.: +91-86990-31147
}

Received: 22 November 2018; Accepted: 3 January 2019; Published: 10 January 2019

check for updates

\begin{abstract}
Fuzzy graphs (FGs) and their generalizations have played an essential role in dealing with real-life problems involving uncertainties. The goal of this article is to show some serious flaws in the existing definitions of several root-level generalized FG structures with the help of some counterexamples. To achieve this, first, we aim to improve the existing definition for interval-valued FG, interval-valued intuitionistic FG and their complements, as these existing definitions are not well-defined; i.e., one can obtain some senseless intervals using the existing definitions. The limitations of the existing definitions and the validity of the new definitions are supported with some examples. It is also observed that the notion of a single-valued neutrosophic graph (SVNG) is not well-defined either. The consequences of the existing definition of SVNG are discussed with the help of examples. A new definition of SVNG is developed, and its improvement is demonstrated with some examples. The definition of an interval-valued neutrosophic graph is also modified due to the shortcomings in the current definition, and the validity of the new definition is proved. An application of proposed work is illustrated through a decision-making problem under the framework of SVNG, and its performance is compared with existing work.
\end{abstract}

Keywords: interval-valued fuzzy graph; intuitionistic fuzzy graph; interval-valued intuitionistic fuzzy graph; single-valued neutrosophic graph; interval-valued neutrosophic graph; complement

\section{Introduction}

The framework of the fuzzy set (FS) was introduced by Zadeh [1] in 1965 as a generalization of crisp sets, which describe the membership of an object to a set by assigning a membership grade from [0,1]. The concept of FS was further generalized to the interval-valued fuzzy set (IVFS) in [2] where the membership grade is defined by closed sub-intervals $\left[S^{L}, S^{U}\right] \subseteq[0,1]$. The idea of FS was further generalized to an enhanced framework of the intuitionistic fuzzy set (IFS) in [3] by considering the degree of non-membership of an object as well as its membership grade, such that the sum of the degrees is less than one. Later on, Atanassov and Gargov [4] extended the theory of IFS to an 
interval-valued IFS (IVIFS). To consider the neutral opinion or abstinence information in the analysis, Smarandache introduced a framework of neutrosophic logic and consequently a neutrosophic set [5]. A neutrosophic set is characterized by three kinds of functions describing the degree of membership, abstinence and non-membership of an object. The concept of the single-valued neutrosophic set (SVNS) was developed by Wang et al. [6], characterized by three characteristic functions, named as truth, falsity and indeterminate, with a restriction that their sum is not greater than 3 . The concept of SVNS was further generalized to an interval-valued neutrosophic set (IVNS) in Wang et al. [7] where the membership, abstinence and non-membership grades are defined in terms of closed sub-intervals of the unit interval. Under the above-mentioned sets, various researchers have addressed different kinds of algorithms to solve decision-making problems [8-25].

Further, apart from this, the concept of the fuzzy graph (FG), initially introduced by Kauffman [26], was thoroughly developed by Rosenfeld [27] in 1975. A generalization of FG known as the interval-valued FG (IVFG) was introduced by Akram and Dudek [28] where the nodes and edges are in the form of interval-valued fuzzy numbers (IVFNs). To deal with the study of FGs and IVFG, we refer the readers to the articles in [29-38]. After successful applications, Parvathi and Karunambigai [39] introduced the concept of intuitionistic fuzzy graphs (IFG), which is a generalization of the FG. The concept of interval-valued IFG (IVIFG) is proposed in [40] and some other terms and notions related to IVIFG can be found in [41,42]. Further, by following the notion of SVNS, the concept of the single-valued neutrosophic graph (SVNG) was introduced by Broumi et al. [43] and has been extensively used in several problems such as the shortest path problem [44,45], communication problem [46], and decision-making [47]. The concept of SVNG was further generalized to the interval-valued neutrosophic graph (IVNG) in [48], where the membership, abstinence and non-membership grades are described by closed subintervals of the unit interval. The framework of IVNG is the most sophisticated among all existing graph structures. For some other work on IVNG, one may refer to [49-51].

In the theory of fuzzy algebraic structures and from the above literature survey, we found some serious shortcomings which motivate us to develop some new definitions for the existing concepts. The problems in the existing literature and steps toward their solution are discussed item by item below.

(1) It is observed that the concept of IVFG [28] has some limitations which lead us to some undefined results. The lower and upper values of the edge interval in IVFG are defined as $\hat{\mathrm{S}}^{L}\left(v_{i}, v_{j}\right) \leq$ $\min \left(S^{L}\left(v_{i}\right), S^{L}\left(v_{j}\right)\right)$ and $\hat{S}^{U}\left(v_{i}, v_{j}\right) \leq \min \left(S^{U}\left(v_{i}\right), S^{U}\left(v_{j}\right)\right)$. According to this definition for two adjacent vertices $(0.2,0.4)$ and $(0.2,0.3)$, we obtained an undefined edge value of $(0.2,0.0)$ by the above approach. The same type of problem occurs in the framework of IVIFG [40] in membership as well as non-membership intervals. Further, the existing definition of IVIFG is not a generalization of IFG; therefore, one must develop a definition for IVIFG which clearly generalizes IFG. These types of flaws in the existing literature lead us to develop some new definitions for IVFG and IVIFG;

(2) The lower and upper values of edges in the complement of an IVFG are defined as $\left(\hat{\mathrm{S}}^{L}\right)^{c}\left(v_{i}, v_{j}\right)=\min \left(S^{L}\left(v_{i}\right), S^{L}\left(v_{j}\right)\right)-\hat{\mathrm{S}}^{L}\left(\left(v_{i}, v_{j}\right)\right)$ and $\left(\hat{\mathrm{S}}^{U}\right)^{c}\left(v_{i}, v_{j}\right)=$ $\min \left(S^{U}\left(v_{i}\right), S^{U}\left(v_{j}\right)\right)-\hat{S}^{U}\left(v_{i}, v_{j}\right)$. Let $(0.2,0.5)$ and $(0.2,0.3)$ be two vertices and $(0.1,0.3)$ their edge. Then, upon calculating the complement, we get the corresponding edge value $(0.1,0.0)$ which is an undefined interval. Similar types of flaws exist in the existing definitions of complements of IVIFGs, therefore leading us to develop some new definitions for the complement of IVFG as well as of IVIFG.;

(3) It is observed that the existing definition of SVNG [43] is not a generalization of IFG as claimed in the existing literature. Also, the existing notion of the SVNG and of its complement as defined in [43] is not well posed, as after taking the complement of a SVNG, the resulting graph obtained is not a SVNG. Further, the existing definition of a complement does not satisfy the property 
$\left(G^{c}\right)^{c}=G$. These facts are described briefly in Section 5, and based on these defects, a new definition for SVNG and its complement have been developed and their validity is proved;

(4) Finally, we improve the definition of the IVNG as the existing definition contradicts the fact that IVNG is a generalization of IVIFG and IVFG. Further, the existing definition of the complement of IVNG is not well defined, which is described with the help of examples, and a new definition for complements is proposed and validated with examples.

The rest of the article is organized as follows: Section 1 provides a historical background of FGs and their generalized algebraic structures. The motivation and aim of our proposed work is also discussed in this section. In Section 2, some basic concepts of FGs and IFGs are discussed and supported with examples. Section 3 is based on a description of the limitations of IVFGs and IVIFGs and some improvements in their basic definitions. In Section 4, we discuss the drawbacks of the complements of IVFG and IVIFG and propose new definitions of complements along with some examples in their support. In Section 5, the drawbacks of the existing concepts of SVNGs, IVNGs and their complements are described. Further, some new improved definitions are proposed for SVNG, IVNGs and the complement of IVNG, supported by some examples. Section 6 is based on an application of SVNGs in decision-making, while Section 7 provides a summary of the article along with some future work.

\section{Basic Concepts}

In this section, some definitions of FG and its complement are defined and demonstrated with the help of an example. The primary definition of IFG is also discussed in this section, followed by an example for illustration.

Definition 1. [27] An FG is a pair $G=(V, E)$ where $V$ is the set of nodes and $E$ is the collection of edges between these nodes such that

(1) Every $v \in V$ is characterized by a function $S: V \rightarrow[0,1]$ denoting the degree of membership of $v \in V$;

(2) Every $e \in E$ is characterized by a function $\hat{\mathrm{S}}: V \times V \rightarrow[0,1]$ denoting the degree of membership $e \in V \times V$ satisfying the condition $\hat{\mathrm{S}}\left(v_{i}, v_{j}\right) \leq \min \left(S\left(v_{i}\right), S\left(v_{j}\right)\right)$.

Definition 2. [29] The complement of $F G G=(V, E)$ is defined by $G^{c}=\left(V^{c}, E^{c}\right)$ where $V^{c}=V$ and the membership grade of $e \in E$ is defined by $(\hat{\mathrm{S}})^{c}\left(v_{i}, v_{j}\right)=\min \left(S\left(v_{i}\right), S\left(v_{j}\right)\right)-\hat{\mathrm{S}}\left(\left(v_{i}, v_{j}\right)\right)$.

Example 1. The following Figure 1 is an example of an FG while Figure 2 represents its complement.

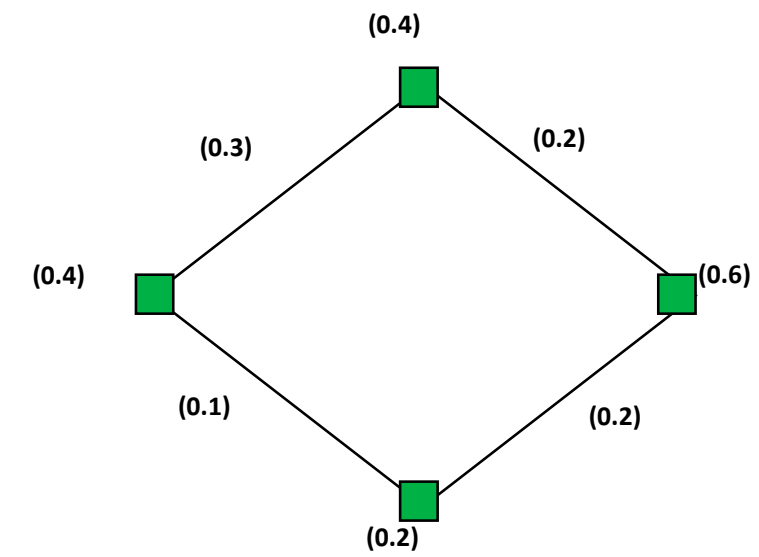

Figure 1. Fuzzy graph (FG) compatible with Definition 1. 


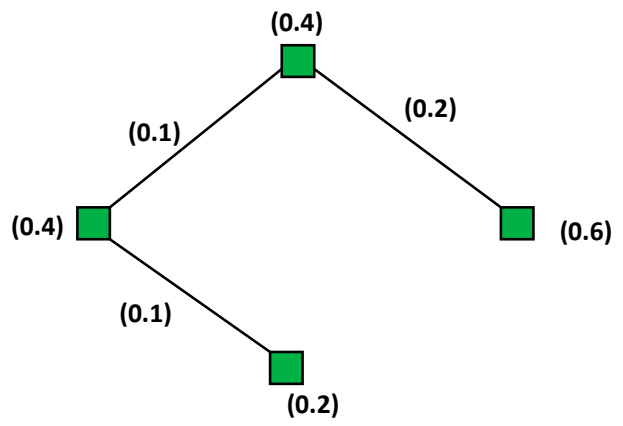

Figure 2. Complement of FG depicted in Figure 1.

Definition 3. [39] An IFG is a duplet $G=(V, E)$ where the set of nodes is denoted by $V$ and $E$ is the collection of edges between these nodes such that

(1) Every $v \in V$ is characterized by two functions $S: V \rightarrow[0,1]$ and $D: V \rightarrow[0,1]$ denoting the membership and non-membership degree of $v \in V$ which satisfies the condition that $0 \leq S+D \leq 1$. Moreover, the term $R$ defined by $R=1-S-D$, denotes the hesitancy level of $\in E$;

(2) Every $e \in E$ is characterized by two functions $\hat{\mathrm{S}}: V \times V \rightarrow[0,1]$ and $Đ: V \times V \rightarrow[0,1]$ denoting the membership and non-membership degree of $e \in V \times V$ satisfying the conditions:

$$
\begin{gathered}
\hat{\mathrm{S}}\left(v_{i}, v_{j}\right) \leq \min \left(S\left(v_{i}\right), S\left(v_{j}\right)\right) \\
\mathrm{Ð}\left(v_{i}, v_{j}\right) \leq \max \left(D\left(v_{i}\right), D\left(v_{j}\right)\right)
\end{gathered}
$$

with a condition that $0 \leq \hat{\mathrm{S}}+\mathrm{D} \leq 1$. Moreover, the term $\check{\mathrm{R}}$ denotes the hesitancy level of $e \in E$ such that $\check{\mathrm{R}}=1-\hat{\mathrm{S}}-$ Đ.

Example 2. The following Figure 3 is an example of an IFG.

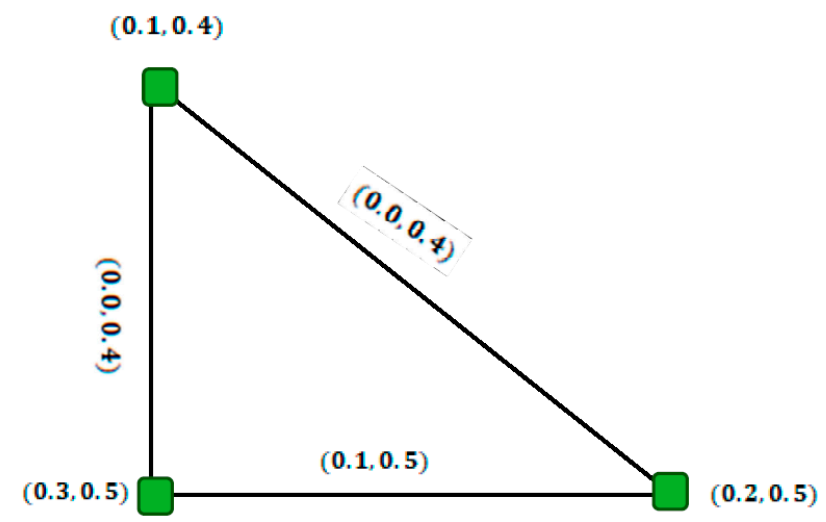

Figure 3. Intuitionistic fuzzy graph (IFG) compatible with Definition 2.

The rest of the basic notions are discussed in Sections 3-5, in which we present a comparative analysis with our proposed work.

\section{Improvements in Interval-Valued Fuzzy Graphs and Interval-Valued Intuitionistic Fuzzy Graphs}

In this section, first, the existing definitions of IVFG and IVIFG are reviewed and the shortcomings of these algebraic structures are pointed out with the help of examples. New definitions for IVFG and IVIFG are developed and their fitness is verified with the help of some examples. 
First, we review the definition of IVFG defined in [28] and provide an example to show the limitation of the definitions.

Definition 4. [28] An IVFG is a duplet $G=(V, E)$ where $V$ denotes a collection of nodes and $E$ denotes the collection of edges between these vertices such that

(1) Every $v \in V$ is characterized by a function $S$ representing the membership degree of $v \in V$. Basically, $S=\left[S^{L}, S^{U}\right]$ is a closed subinterval $[0,1]$;

(2) Every $e \in E$ is characterized by a function $\hat{S}$ denoting the degree of membership $e \in V \times V$. Basically, $\hat{\mathrm{S}}=\left[\hat{\mathrm{S}}^{L}, \hat{\mathrm{S}}^{U}\right]$ satisfying the conditions:

$$
\hat{S}^{L}\left(v_{i}, v_{j}\right) \leq \min \left(S^{L}\left(v_{i}\right), S^{L}\left(v_{j}\right)\right) \hat{S}^{U}\left(v_{i}, v_{j}\right) \leq \min \left(S^{U}\left(v_{i}\right), S^{U}\left(v_{j}\right)\right)
$$

Example 3. Consider the following Figure 4, where we observed that, while determining the edge values, we get undefined intervals as highlighted. This shows that the current notion of an IVFG is not satisfactory, which leads us to develop a new definition.

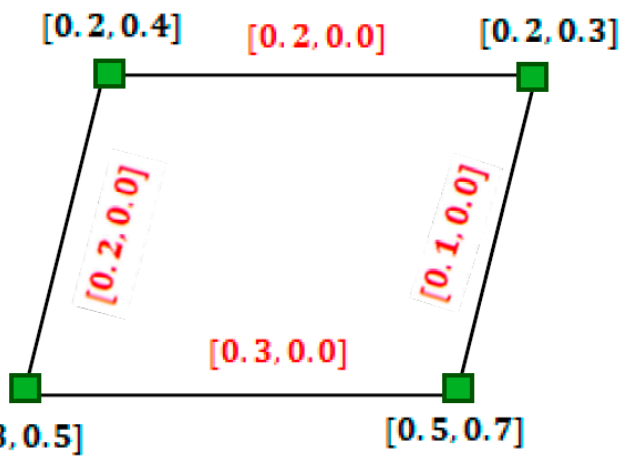

Figure 4. Interval-valued fuzzy graph containing undefined intervals.

Definition 5. An IVFG is a duplet $G=(V, E)$ where $V$ denotes a collection of nodes and $E$ denotes the collection of edges between these vertices such that

(1) Every $v \in V$ is characterized by a function $S$ representing the membership grade of $v \in V$. Basically, $S=\left[S^{L}, S^{U}\right]$ is a closed subinterval of the unit interval [0,1];

(2) Every $e \in E$ is characterized by a function $\hat{S}$ denoting the membership grade of $e \in V \times V$. The closed subinterval $\hat{\mathrm{S}}=\left[\hat{\mathrm{S}}^{L}, \hat{\mathrm{S}}^{U}\right]$ satisfying the conditions:

$$
\begin{gathered}
\hat{S}^{L}\left(v_{i}, v_{j}\right) \leq \min \left(S^{L}\left(v_{i}\right), S^{L}\left(v_{j}\right)\right) \text { and } \\
\hat{S}^{U}\left(v_{i}, v_{j}\right) \leq \min \left(S^{U}\left(v_{i}\right), S^{U}\left(v_{j}\right)\right) \operatorname{such} \text { that } \hat{S}^{U}\left(v_{i}, v_{j}\right) \geq \min \left(S^{L}\left(v_{i}\right), S^{L}\left(v_{j}\right)\right) .
\end{gathered}
$$

This definition is supported with the help of following example in which we show that none of the intervals is undefined and that Definition 5 works perfectly.

Example 4. The following IVFG depicted in Figure 5 is in accordance with Definition 5. 


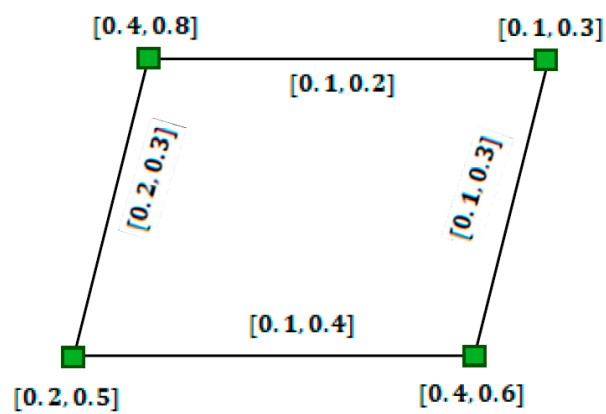

Figure 5. Interval-valued fuzzy graph compatible with Definition 5.

Next, we provide a critical study of IVIFGs with a definition which is based on IVIFG which yields undefined closed sub-intervals. First, we review the existing definition and the existing shortcomings with the help of examples. Then, the new definition is developed and supported by an example.

Definition 6. [40] An IVIFG is a duplet $G=(V, E)$ where the set of nodes is denoted by $V$ and $E$ is the collection of edges between these nodes such that

(1) Every $v \in V$ is characterized by two functions $S$ and $D$ denoting the membership and non-membership grades of $v \in V$. Basically, $S=\left[S^{L}, S^{U}\right]$ and $D=\left[D^{L}, D^{U}\right]$ are closed subintervals of the unit interval $[0,1]$ with a condition that $0 \leq S^{U}+D^{U} \leq 1$. Moreover, the term $R=\left[R^{L}, R^{U}\right]$ denote the hesitancy level of $v \in V$ such that $R^{U}=1-S^{L}-D^{L}$ and $R^{L}=1-S^{U}-D^{U}$.

(2) Every $e \in E$ is characterized by two functions $\hat{S}$ and $Đ$ denoting the membership and non-membership

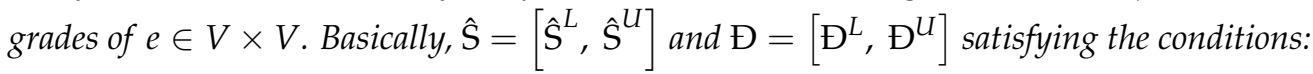

$$
\begin{array}{cc}
\hat{\mathrm{S}}^{L}\left(v_{i}, v_{j}\right) \leq \min \left(S^{L}\left(v_{i}\right), S^{L}\left(v_{j}\right)\right) & \hat{\mathrm{S}}^{U}\left(v_{i}, v_{j}\right) \leq \min \left(S^{U}\left(v_{i}\right), S^{U}\left(v_{j}\right)\right) \\
\mathrm{Ð}^{L}\left(v_{i}, v_{j}\right) \geq \max \left(D^{L}\left(v_{i}\right), D^{L}\left(v_{j}\right)\right) & \mathrm{Ð}^{U}\left(v_{i}, v_{j}\right) \geq \max \left(D^{U}\left(v_{i}\right), D^{U}\left(v_{j}\right)\right)
\end{array}
$$

provided that $0 \leq \hat{\mathrm{S}}^{U}+\bigoplus^{U} \leq 1$. Moreover, the term $\check{\mathrm{R}}=\left[\check{\mathrm{R}}^{L}, \check{\mathrm{R}}^{U}\right]$ denote the hesitancy level of e $\in E$ such that $\check{\mathrm{R}}^{U}=1-\hat{\mathrm{S}}^{L}-\mathrm{Ð}^{L}$ and $\check{\mathrm{R}}^{L}=1-\hat{\mathrm{S}}^{U}-\mathrm{Ð}^{U}$.

Definition 6 seems to be weak in two ways. The first reason is that IVIFG is a generalization of IFG where the non-membership grade of edge is defined as $Đ\left(v_{i}, v_{j}\right) \leq \max \left(D\left(v_{i}\right), D\left(v_{j}\right)\right)$, which is not followed in defining IVIFG, raising a question regarding its perfection. Another shortcoming in Definition 6 is that we may sometimes have obtained undefined closed intervals, which should be avoided. For further illustration, consider the example as follows.

Example 5. Consider the following IVIFG in Figure 6, where it is observed that we get some undefined intervals by applying Definition 6. The undefined closed intervals are highlighted. 


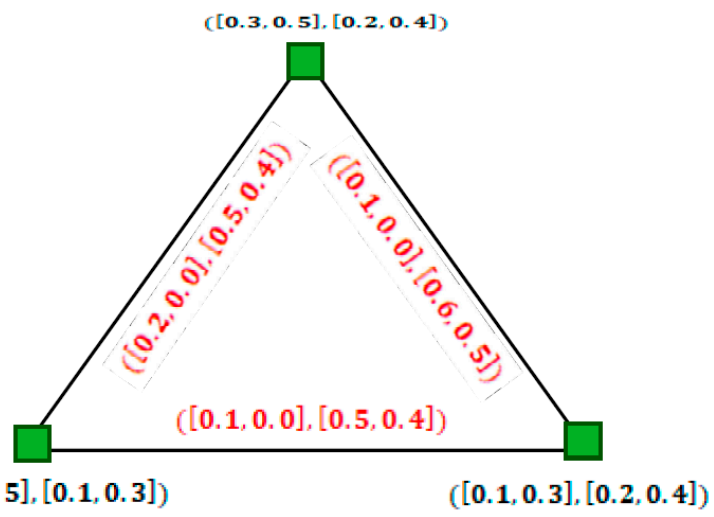

Figure 6. Interval-valued intuitionistic fuzzy graph (IVIFG) obtained using Definition 6 with undefined intervals.

Keeping in mind the weakness of Definition 6 as demonstrated by Example 5, we propose a new definition of IVIFG which is well defined and truly a generalization of IFG.

Definition 7. An IVIFG is a pair $G=(V, E)$ where the set of nodes is denoted by $V$ and $E$ is the collection of edges between these nodes such that

(1) Every $v \in V$ is characterized by two functions $S$ and $D$ denoting the membership and non-membership grades of $v \in V$. Basically, $S=\left[S^{L}, S^{U}\right]$ and $D=\left[D^{L}, D^{U}\right]$ are closed subintervals of the unit interval $[0,1]$ with a condition that $0 \leq S^{U}+D^{U} \leq 1$. Moreover, the term $R=\left[R^{L}, R^{U}\right]$ denote the hesitancy level of $v \in V$ such that $R^{U}=1-S^{L}-D^{L}$ and $R^{L}=1-S^{U}-D^{U}$;

(2) Every $e \in E$ is characterized by two functions $\hat{S}$ and $Đ$ denoting the membership and non-membership

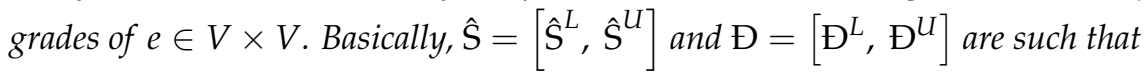

$$
\begin{gathered}
\hat{\mathrm{S}}^{L}\left(v_{i}, v_{j}\right) \leq \min \left(S^{L}\left(v_{i}\right), S^{L}\left(v_{j}\right)\right) . \\
\hat{\mathrm{S}}^{U}\left(v_{i}, v_{j}\right) \leq \min \left(S^{U}\left(v_{i}\right), S^{U}\left(v_{j}\right)\right) \operatorname{such} \text { that } \hat{\mathrm{S}}^{U}\left(v_{i}, v_{j}\right) \geq \min \left(S^{L}\left(v_{i}\right), S^{L}\left(v_{j}\right)\right) . \\
\bigoplus^{L}\left(v_{i}, v_{j}\right) \leq \max \left(D^{L}\left(v_{i}\right), D^{L}\left(v_{j}\right)\right) . \\
\mathrm{Ð}^{U}\left(v_{i}, v_{j}\right) \leq \max \left(D^{U}\left(v_{i}\right), D^{U}\left(v_{j}\right)\right) \operatorname{such} \text { that } \bigoplus^{U}\left(v_{i}, v_{j}\right) \geq \max \left(D^{L}\left(v_{i}\right), D^{L}\left(v_{j}\right)\right) .
\end{gathered}
$$

provided that $0 \leq \hat{\mathrm{S}}^{U}+\bigoplus^{U} \leq 1$. Moreover, the term $\breve{\mathrm{R}}=\left[\breve{\mathrm{R}}^{L}, \breve{\mathrm{R}}^{U}\right]$ denote the hesitancy level of e $\in E$ such that $\check{\mathrm{R}}^{U}=1-\hat{\mathrm{S}}^{L}-\mathrm{Ð}^{L}$ and $\check{\mathrm{R}}^{L}=1-\hat{\mathrm{S}}^{U}-\mathrm{Ð}^{U}$.

The following example shows that Definition 7 improves the concept of IVIFG and that there is no chance of getting undefined intervals.

Example 6. Consider the graph depicted in Figure 7 demonstrating the new definition of IVIFG. 


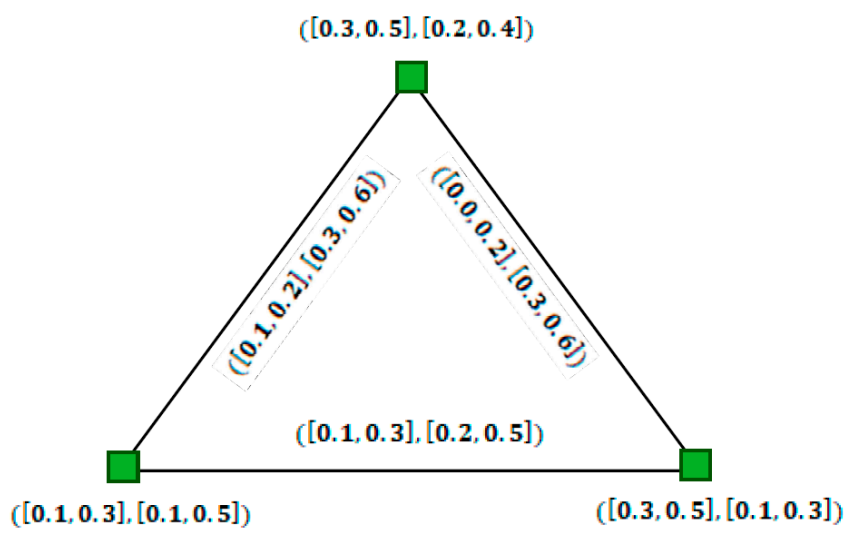

Figure 7. Interval-valued intuitionistic fuzzy graph.

The next section is based on the shortcomings of existing definitions of the complement of an IVFG and of an IVIFG together with the development of new definitions. The existing and new definitions are demonstrated with examples.

\section{New Definitions for the Complement of the Interval-Valued Fuzzy Graph and Interval-Valued Intuitionistic Fuzzy Graph}

It is observed that the definition of the complement of IVFG did not provide justifiable results on some occasions. The results obtained using the current definition of IVFG leads us to obtain some undefined intervals, and therefore in this section we propose a new definition for the complement of IVFG.

For the first time, the complement of IVFG was defined in [38]. First, we review the existing definition and, with the help of an example, we point out its shortcomings.

Definition 8. [38] The complement of an IVFG $G=(V, E)$ is defined by $G^{c}=\left(V^{c}, E^{c}\right)$ where $V^{c}=V$ and the membership and non-membership grades of E satisfying the conditions:

$$
\begin{aligned}
& \left(\hat{S}^{L}\right)^{c}\left(v_{i}, v_{j}\right)=\min \left(S^{L}\left(v_{i}\right), S^{L}\left(v_{j}\right)\right)-\hat{S}^{L}\left(\left(v_{i}, v_{j}\right)\right) \\
& \left(\hat{S}^{U}\right)^{c}\left(v_{i}, v_{j}\right)=\min \left(S^{U}\left(v_{i}\right), S^{U}\left(v_{j}\right)\right)-\hat{S}^{U}\left(v_{i}, v_{j}\right)
\end{aligned}
$$

Example 7. In the following, consider an IVFG depicted in Figure 8, then based on the existing definition 8, we compute its complement and it is given in Figure 9. It is observed from the Figure 9 that there are undefined intervals which are highlighted in red color.

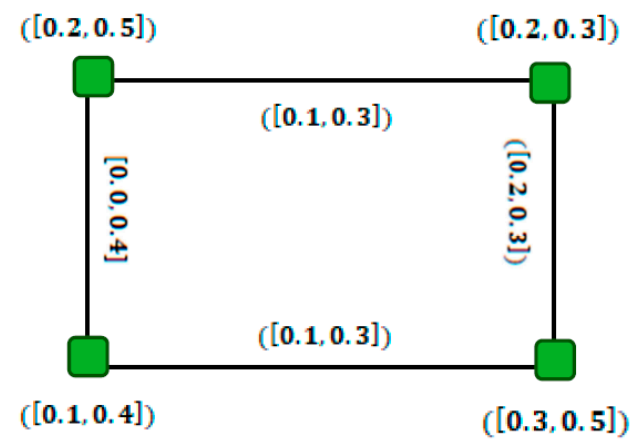

Figure 8. Interval-valued fuzzy graph. 


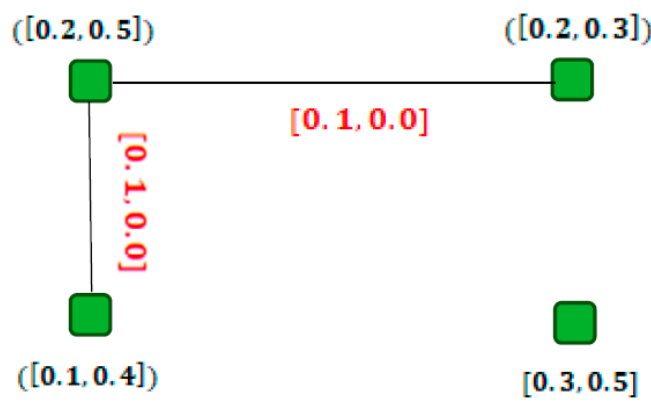

Figure 9. Complement of graph depicted in Figure 8 based on Definition 8, giving us undefined intervals.

Another definition of the complement of IVFG is defined in [11] which is described as follows:

Definition 9. [28] The complement of an IVFG $G=(V, E)$ is defined by $G^{c}=\left(V^{c}, E^{c}\right)$ where $V^{c}=V$ and the membership functions of $E^{\mathcal{C}}$ satisfies the following:

$$
\begin{aligned}
& \left(\hat{\mathrm{S}}^{L}\right)^{c}\left(v_{i}, v_{j}\right)=\left\{\begin{array}{ccc}
0 & \text { if } & S^{L}\left(v_{i}, v_{j}\right) \geq 0 \\
\min \left(S^{L}\left(v_{i}\right), S^{L}\left(v_{j}\right)\right) & \text { if } & S^{L}\left(v_{i}, v_{j}\right)=0
\end{array}\right\} \\
& 0 \quad \text { if } \quad S^{U}\left(v_{i}, v_{j}\right) \geq 0 \\
& \left(\hat{\mathrm{S}}^{U}\right)^{c}\left(v_{i}, v_{j}\right)=\left\{\begin{array}{ccc}
0 & \text { if } \quad S^{U}\left(v_{i}, v_{j}\right)=0
\end{array}\right\}
\end{aligned}
$$

This definition is not well defined as it is not valid for all types of IVFGs. The problem in this definition of the complement is that it does not possesses the property $\left(G^{c}\right)^{c}=G$. This is demonstrated in the following example.

Example 8. The complement of IVFG as exhibited in Figure 8 is depicted in Figure 10 below and it is observed that all the edges have disappeared surprisingly, which seems insignificant. Now, we determine the complement of Figure 10 again and put it on display in Figure 11, which clearly indicates that the basic result of the complement, i.e., $\left(G^{c}\right)^{c}=G$, does not hold true for Definition 9 .

$([0.2,0.5])$
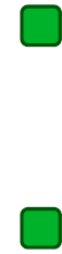

$([0.1,0.4])$
$([0.2,0.3])$

$[0.3,0.5]$

Figure 10. Complement of Figure 8. 


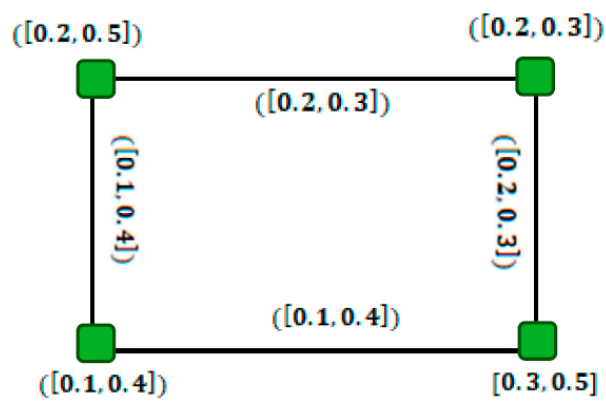

Figure 11. Complement of Figure 10 based on Definition 9.

Moreover, Definition 9 is used to find the complement of a complete IVFG in [28] by Akram and Dudek, where this definition possesses the property of a complement; i.e., $\left(G^{c}\right)^{c}=G$. However, we need a definition of a complement which can be used for the entire range of IVFG and not only complete IVFGs; therefore, we develop a new well-defined definition for the complement of IVFGs as follows.

Definition 10. The complement of IVFG $G=(V, E)$ is defined by $G^{c}=\left(V^{c}, E^{c}\right)$ where $V^{c}=V$ and the membership grades of $E$ satisfies the following properties:

$$
\begin{aligned}
& \left(\hat{\mathrm{S}}^{L}\right)^{c}\left(v_{i}, v_{j}\right)=\min \left(S^{L}\left(v_{i}\right), S^{L}\left(v_{j}\right)\right)-\hat{\mathrm{S}}^{L}\left(\left(v_{i}, v_{j}\right)\right) \\
& \left(\hat{\mathrm{S}}^{U}\right)^{c}\left(v_{i}, v_{j}\right)=\min \left(S^{U}\left(v_{i}\right), S^{U}\left(v_{j}\right)\right)-\hat{S}^{U}\left(v_{i}, v_{j}\right)+\min \left(S^{L}\left(v_{i}\right), S^{L}\left(v_{j}\right)\right) .
\end{aligned}
$$

In the following examples, we not only demonstrate the new definition but also verify that the basic property of the notion of the complement as presented in Definition 10 is available; i.e., $\left(G^{c}\right)^{c}=G$.

Example 9. In what follows, Figure 12 represents the complement of Figures 8 and 13 represents the complement of Figure 12. Hence, as we claimed, the equality $\left(G^{c}\right)^{c}=G$ holds true for our proposed new definition.

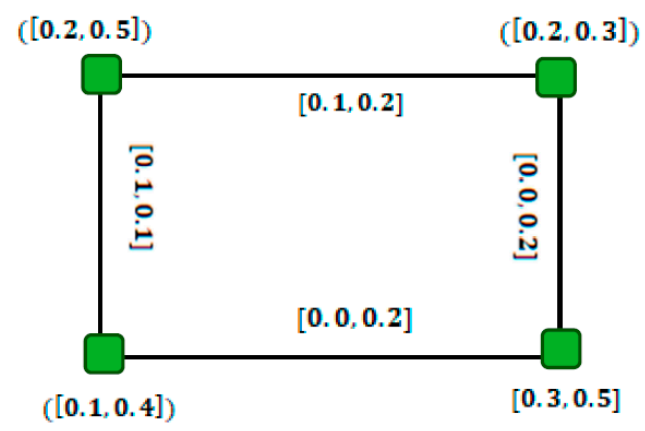

Figure 12. Complement of graph depicted in Figure 8. 


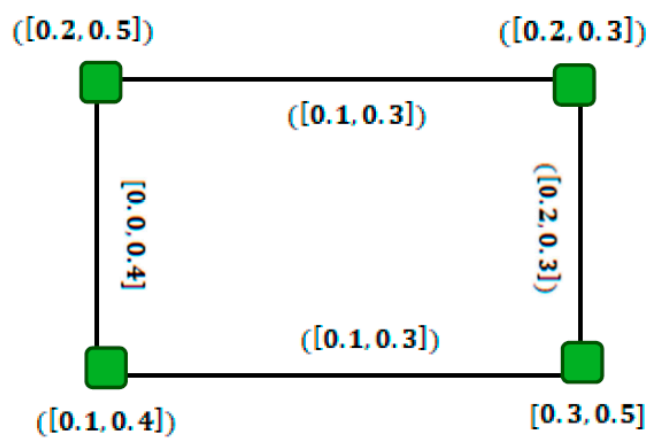

Figure 13. The complement of graph depicted in Figure 12.

Now, we develop the definition of the complement for IVIFGs because the existing definition does not make any sense in some cases, as we described for IVFGs.

Definition 11. The complement of IVIFG $G=(V, E)$ is defined by $G^{c}=\left(V^{c}, E^{c}\right)$ where $V^{c}=V$ and the membership and non-membership grades of E satisfied the conditions:

$$
\begin{gathered}
\left(\hat{\mathrm{S}}^{L}\right)^{c}\left(v_{i}, v_{j}\right)=\min \left(S^{L}\left(v_{i}\right), S^{L}\left(v_{j}\right)\right)-\hat{\mathrm{S}}^{L}\left(\left(v_{i}, v_{j}\right)\right) . \\
\left(\hat{\mathrm{S}}^{U}\right)^{c}\left(v_{i}, v_{j}\right)=\min \left(S^{U}\left(v_{i}\right), S^{U}\left(v_{j}\right)\right)-\hat{\mathrm{S}}^{U}\left(v_{i}, v_{j}\right)+\min \left(S^{L}\left(v_{i}\right), S^{L}\left(v_{j}\right)\right) . \\
\left(\Xi^{L}\right)^{c}\left(v_{i}, v_{j}\right)=\max \left(D^{L}\left(v_{i}\right), D^{L}\left(v_{j}\right)\right)-\mathrm{Ð}^{L}\left(\left(v_{i}, v_{j}\right)\right) . \\
\left(\Xi^{U}\right)^{c}\left(v_{i}, v_{j}\right)=\max \left(D^{U}\left(v_{i}\right), D^{U}\left(v_{j}\right)\right)-\Xi^{U}\left(v_{i}, v_{j}\right)+\max \left(D^{L}\left(v_{i}\right), D^{L}\left(v_{j}\right)\right) .
\end{gathered}
$$

Example 10. Consider the following IVIFGs whose graph is shown in Figure 14 while its complement graph is shown in Figure 15. Moreover, through some easy calculations, one can easily verify that $\left(G^{c}\right)^{c}=G$.

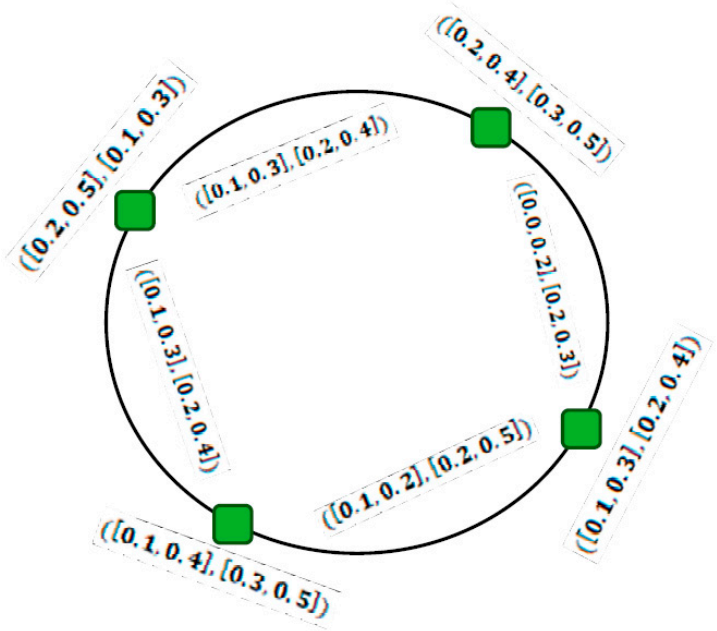

Figure 14. Interval-valued intuitionistic fuzzy graph. 


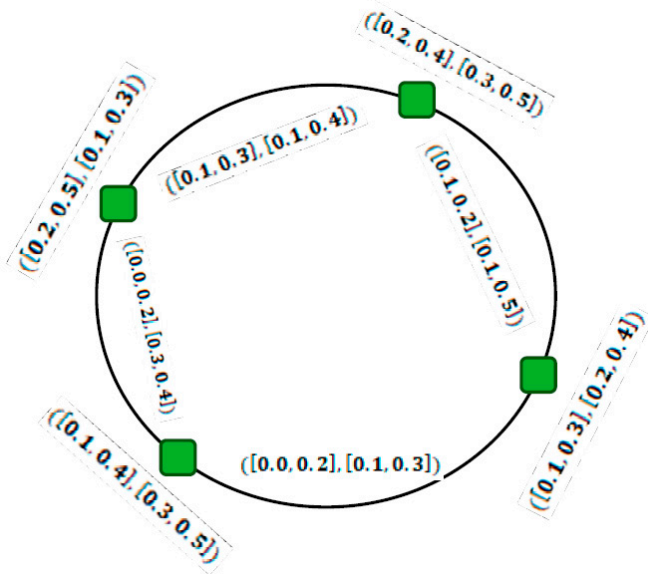

Figure 15. Complement of IVIFG depicted in Figure 14.

In the next section, we discuss the limitations of SVNGS, IVNGs, and their complements. In addition, we develop some new valid definitions.

\section{Improvements in Single-Valued Neutrosophic Graphs and Interval-Valued Neutrosophic Graphs}

In this section, we study the SVNGs proposed in [26] and IVNGs developed in [48] and we describe their shortcomings with some examples. Then, a new definition is proposed for both SVNGs and IVNGs, and their complement is discussed. In support of these new definitions, we present some examples.

Definition 12. [43] An SVNG is a pair $G=(V, E)$ where $V$ is the set of nodes and $E$ is the collection of edges between these nodes such that

(1) Every $v \in V$ is characterized by three functions $S: V \rightarrow[0,1], I: V \rightarrow[0,1]$ and $D: V \rightarrow[0,1]$ denoting the membership, neutral and non-membership grades of $v \in V$ which satisfy $0 \leq S+I+D \leq 3$;

(2) Every $e \in E$ is characterized by three functions $\hat{\mathrm{S}}: V \times V \rightarrow[0,1], \hat{\mathrm{I}}: V \times V \rightarrow[0,1]$ and $\mathrm{Ð}: V \times V \rightarrow[0,1]$ denoting the membership, neutral and non-membership grades of $e \in V \times V$ satisfies

$$
\begin{gathered}
\hat{\mathrm{S}}\left(v_{i}, v_{j}\right) \leq \min \left(S\left(v_{i}\right), S\left(v_{j}\right)\right) \\
\hat{\mathrm{I}}\left(v_{i}, v_{j}\right) \geq \max \left(I\left(v_{i}\right), I\left(v_{j}\right)\right) \\
\mathrm{Ð}\left(v_{i}, v_{j}\right) \geq \max \left(D\left(v_{i}\right), D\left(v_{j}\right)\right)
\end{gathered}
$$

which satisfy the inequality $0 \leq \hat{\mathrm{S}}+\hat{\mathrm{I}}+Đ \leq 3$.

It is observed that this definition is not suitable and needs to be modified for two reasons. The first reason lies in the fact that as SVNG is a generalization of IFG, by exempting the indeterminacy value, Definition 12 should reduce to Definition 3. However, this does not happen, as the non-membership degree of an edge in IFG and in SVNG are defined in a different way; i.e., the non-membership degree for IFG is defined as $\mathrm{Ð}\left(v_{i}, v_{j}\right) \leq \max \left(D\left(v_{i}\right), D\left(v_{j}\right)\right)$ while in case of SVNGs it is defined as $\mathrm{Ð}\left(v_{i}, v_{j}\right) \geq \max \left(D\left(v_{i}\right), D\left(v_{j}\right)\right)$.

The second reason is based on the definition of complement of SVNGs, as the complement of an SVNG needs to be an SVNG, which did not happen on some occasions. We present the current definition of the complement of an SVNG and with the help of an example describe that the complement of an SVNG is not well defined. 
Definition 13. [43] The complement of an $S V N G G=(V, E)$ is defined by $G^{c}=\left(V^{c}, E^{c}\right)$ where $V^{c}=V$ and the membership, neutral value and non-membership grades of $E$ satisfy the conditions:

$$
\begin{gathered}
(\hat{\mathrm{S}})^{c}\left(v_{i}, v_{j}\right)=\min \left(S\left(v_{i}\right), S\left(v_{j}\right)\right)-\hat{\mathrm{S}}\left(\left(v_{i}, v_{j}\right)\right) . \\
(\hat{\mathrm{I}})^{c}\left(v_{i}, v_{j}\right)=\max \left(I\left(v_{i}\right), I\left(v_{j}\right)\right)-\hat{\mathrm{I}}\left(\left(v_{i}, v_{j}\right)\right) . \\
(Ð)^{c}\left(v_{i}, v_{j}\right)=\max \left(D\left(v_{i}\right), D\left(v_{j}\right)\right)-\mathrm{Ð}\left(\left(v_{i}, v_{j}\right)\right) .
\end{gathered}
$$

Keep in mind Definition 13 and consider the following example, where the complement of an SVNG does not remain an SVNG. All this leads to some modification in the basic definition of SVNG which not only generalizes an IFG but is also compatible to satisfy the basic properties of taking complements.

Example 11. In the following figures, Figure 16 represents SVNGs and Figure 17 represents their complement. It is clear from Figure 17 that the complement of an SVNG is not an SVNG.

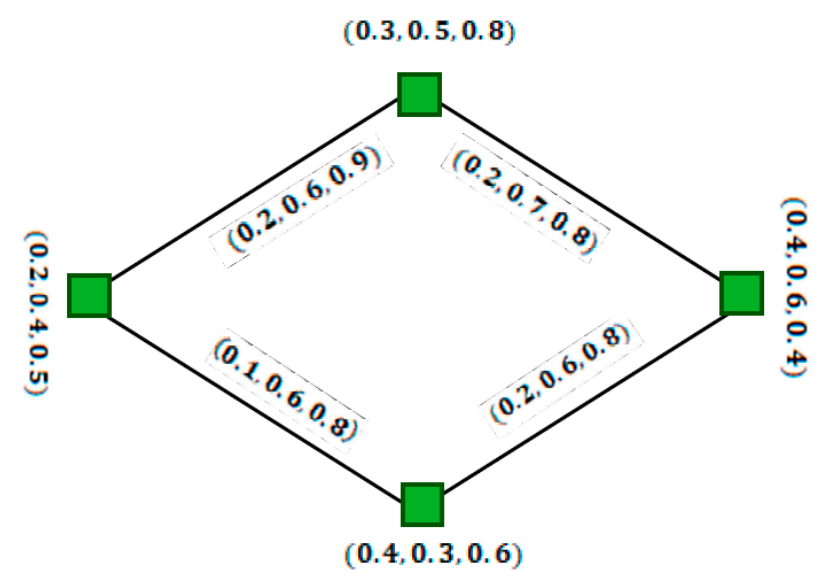

Figure 16. Single-valued neutrosophic graph.

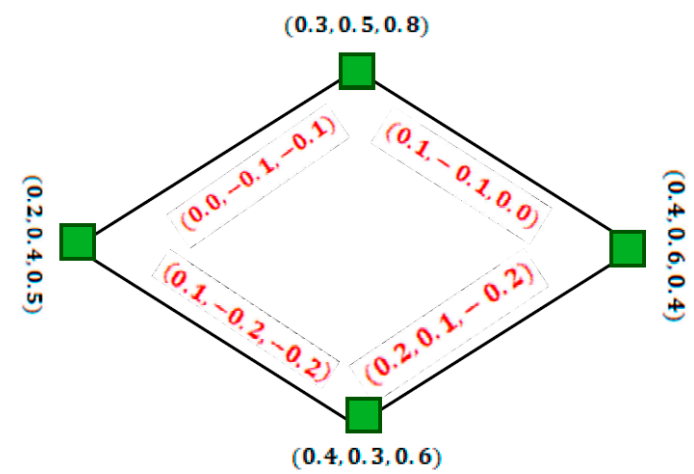

Figure 17. Complement of the SVNG depicted in Figure 16.

Now, we present a new definition for SVNG as a generalization of IFG which is well-defined.

Definition 14. An SVNG is a pair $G=(V, E)$ where $V$ is the set of nodes and $E$ is the collection of edges between these nodes such that

1. Every $v \in V$ is characterized by three functions $S: V \rightarrow[0,1], I: V \rightarrow[0,1]$ and $D: V \rightarrow[0,1]$ denoting the membership, neutral and non-membership grades of $v \in V$ which satisfy the inequality $0 \leq$ $S+I+D \leq 3$; 
2. Every $e \in E$ is characterized by three functions $\hat{\mathrm{S}}: V \times V \rightarrow[0,1], \hat{\mathrm{I}}: V \times V \rightarrow[0,1]$ and $\mathrm{Đ}: V \times V \rightarrow[0,1]$ denoting the membership, neutral and non-membership grades of $e \in V \times V$ satisfying

$$
\begin{aligned}
\hat{\mathrm{S}}\left(v_{i}, v_{j}\right) & \leq \min \left(S\left(v_{i}\right), S\left(v_{j}\right)\right) \\
\hat{\mathrm{I}}\left(v_{i}, v_{j}\right) & \leq \max \left(I\left(v_{i}\right), I\left(v_{j}\right)\right) \\
\mathrm{Ð}\left(v_{i}, v_{j}\right) & \leq \max \left(D\left(v_{i}\right), D\left(v_{j}\right)\right)
\end{aligned}
$$

provided that $0 \leq \hat{\mathrm{S}}+\hat{\mathrm{I}}+\mathrm{Ð} \leq 3$.

Example 12. In the following figures, Figure 18 represents an SVNG compatible with the new definition and Figure 19 represents the complement of the SVNG depicted in Figure 18.

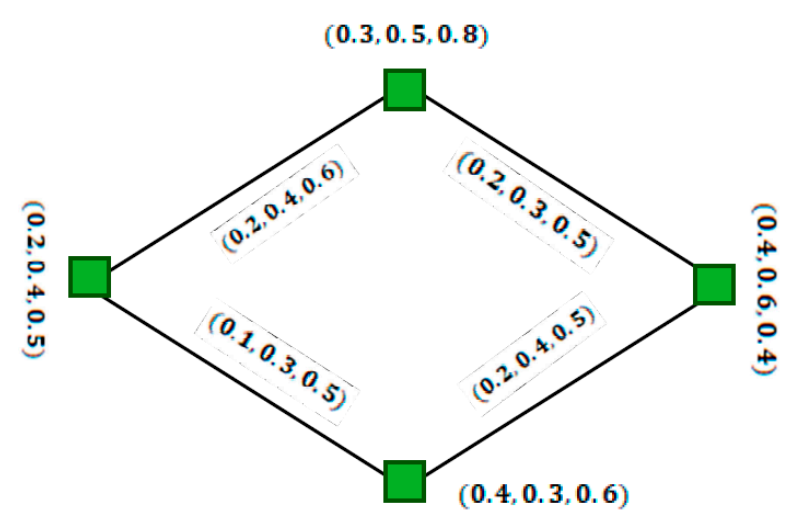

Figure 18. Single-valued neutrosophic graph.

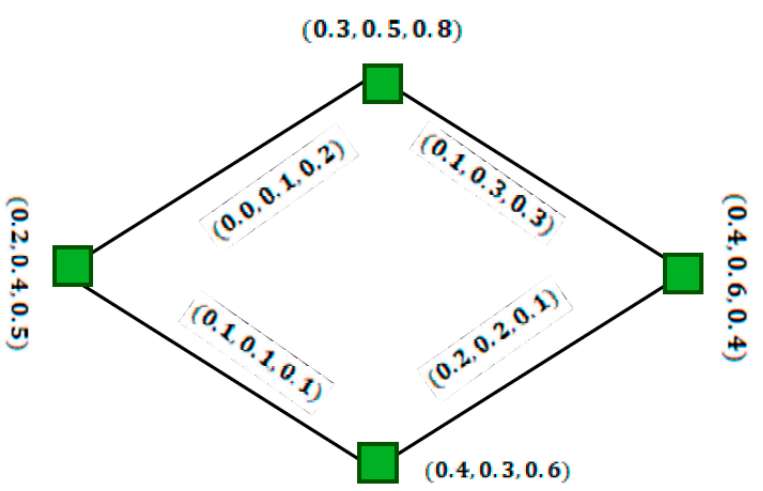

Figure 19. Complement of the graph depicted in Figure 18.

Likewise, in SVNGs the same kinds of flaw exist in the definition of IVNGs. First, we present the existing definition of IVNG and point out its limitation with the help of an example. Then, we develop the new definition for IVNG and support it with an example. After developing the new definition for IVNGs, we discuss the concept of complements for IVNGs by considering the defects in forming complements of IVFG and IVIFG.

Definition 15. [48] An IVNG is a pair $G=(V, E)$ where $V$ is the set of nodes and $E$ is the collection of edges between these nodes such that

1. Every $v \in V$ is characterized by three functions $S, I$ and $D$ denoting the membership, neutral and non-membership grades of $v \in V$. Basically, $S=\left[S^{L}, S^{U}\right], I=\left[I^{L}, I^{U}\right]$ and $D=\left[D^{L}, D^{U}\right]$ are closed subintervals of the unit interval $[0,1]$ which satisfy the inequality $0 \leq S^{U}+I^{U}+D^{U} \leq 3 . ;$ 
2. Every $e \in E$ is characterized by three functions $\hat{\mathrm{S}}, \hat{\mathrm{I}}$ and $\mathrm{D}$ denoting the membership, neutral and

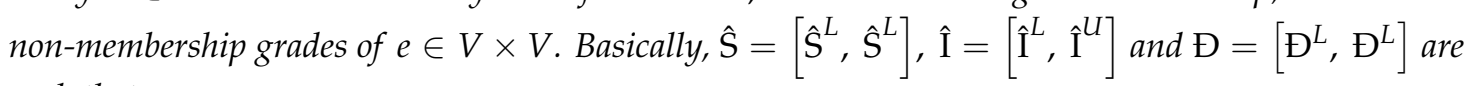
such that:

$$
\begin{array}{cc}
\hat{\mathrm{S}}^{L}\left(v_{i}, v_{j}\right) \leq \min \left(S^{L}\left(v_{i}\right), S^{L}\left(v_{j}\right)\right) & \hat{\mathrm{S}}^{U}\left(v_{i}, v_{j}\right) \leq \min \left(S^{U}\left(v_{i}\right), S^{U}\left(v_{j}\right)\right) \\
\hat{\mathrm{I}}^{L}\left(v_{i}, v_{j}\right) \geq \max \left(I^{L}\left(v_{i}\right), I^{L}\left(v_{j}\right)\right) & \hat{\mathrm{I}}^{U}\left(v_{i}, v_{j}\right) \geq \max \left(I^{U}\left(v_{i}\right), I^{U}\left(v_{j}\right)\right) \\
\mathrm{Ð}^{L}\left(v_{i}, v_{j}\right) \geq \max \left(D^{L}\left(v_{i}\right), D^{L}\left(v_{j}\right)\right) & \mathrm{Ð}^{U}\left(v_{i}, v_{j}\right) \geq \max \left(D^{U}\left(v_{i}\right), D^{U}\left(v_{j}\right)\right)
\end{array}
$$

which satisfy the inequality $0 \leq \hat{\mathrm{S}}^{U}+\hat{\mathrm{I}}^{U}+\mathrm{Ð}^{U} \leq 3$.

Likewise, IVFG and IVIFG are defined, and Definition 15 sometime leads to undefined closed sub-intervals as shown in the following example.

Example 13. Consider the following example of an IVNG as exhibited in Figure 20 based on Definition 15, leading us to some undefined intervals.

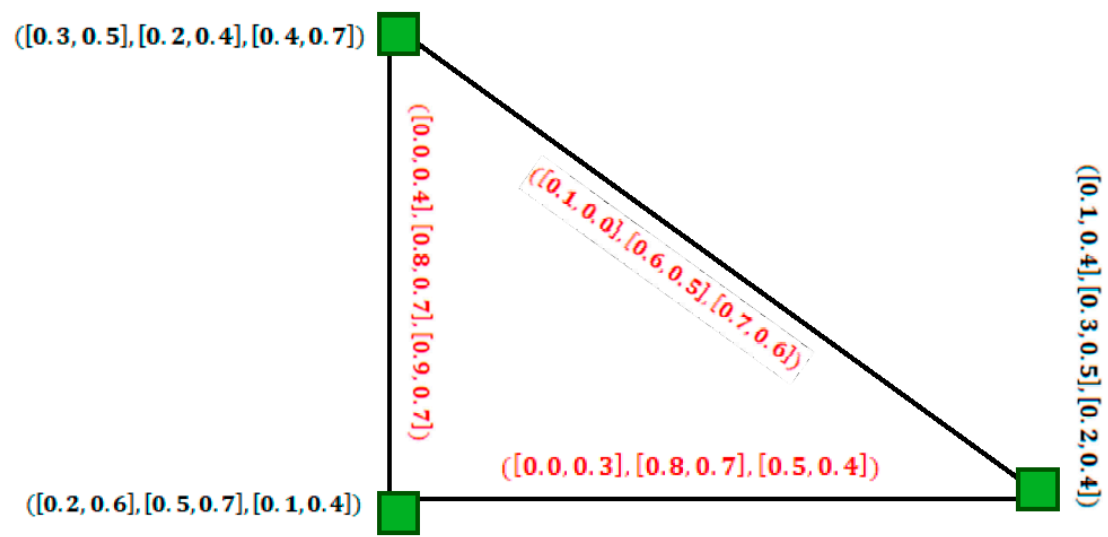

Figure 20. Interval-valued neutrosophic graph with undefined intervals.

Now, we present a new definition of IVNG as follows.

Definition 16. An IVNG is a pair $G=(V, E)$ where $V$ is the set of nodes and $E$ is the collection of edges between these nodes such that

(1) Every $v \in V$ is characterized by three functions $S$, I and $D$ denoting the membership, neutral and non-membership grades of $v \in V$. Basically, $S=\left[S^{L}, S^{U}\right], I=\left[I^{L}, I^{U}\right]$ and $D=\left[D^{L}, D^{U}\right]$ are closed subintervals of the unit interval $[0,1]$ with a condition that $0 \leq S^{U}+I^{U}+D^{U} \leq 3$.;

(2) Every $e \in E$ is characterized by three functions $\hat{\mathrm{S}}$, $\hat{\mathrm{I}}$ and $\mathrm{Ð}$ denoting the membership, neutral and non-membership grades of $e \in V \times V$. Basically $\hat{\mathrm{S}}=\left[\hat{\mathrm{S}}^{L}, \hat{\mathrm{S}}^{L}\right], \hat{\mathrm{I}}=\left[\hat{\mathrm{I}}^{L}, \hat{\mathrm{I}}^{U}\right]$ and $\mathrm{Ð}=\left[\mathrm{\Xi}^{L}, \mathrm{Ð}^{L}\right]$ are such that

$$
\begin{array}{ccc}
\hat{\mathrm{S}}^{L}\left(v_{i}, v_{j}\right) \leq \min \left(S^{L}\left(v_{i}\right), S^{L}\left(v_{j}\right)\right) & \hat{\mathrm{S}}^{U}\left(v_{i}, v_{j}\right) \leq \min \left(S^{U}\left(v_{i}\right), S^{U}\left(v_{j}\right)\right) \\
\hat{\mathrm{I}}^{L}\left(v_{i}, v_{j}\right) \leq \max \left(I^{L}\left(v_{i}\right), I^{L}\left(v_{j}\right)\right) & \hat{\mathrm{I}}^{U}\left(v_{i}, v_{j}\right) \leq \max \left(I^{U}\left(v_{i}\right), I^{U}\left(v_{j}\right)\right) \\
\mathrm{Ð}^{L}\left(v_{i}, v_{j}\right) \leq \max \left(D^{L}\left(v_{i}\right), D^{L}\left(v_{j}\right)\right) & \mathrm{Ð}^{U}\left(v_{i}, v_{j}\right) \leq \max \left(D^{U}\left(v_{i}\right), D^{U}\left(v_{j}\right)\right)
\end{array}
$$

provided that $\hat{\mathrm{S}}^{U}\left(v_{i}, v_{j}\right) \leq \hat{\mathrm{S}}^{L}\left(v_{i}, v_{j}\right), \hat{\mathrm{I}}^{L}\left(v_{i}, v_{j}\right) \leq \hat{\mathrm{I}}^{U}\left(v_{i}, v_{j}\right), \mathrm{Ð}^{L}\left(v_{i}, v_{j}\right) \leq \mathrm{Ð}^{U}\left(v_{i}, v_{j}\right)$ and $0 \leq \hat{\mathrm{S}}^{U}+\hat{\mathrm{I}}^{U}+\mathrm{Ð}^{U} \leq 3$. 
Example 14. Consider the graph depicted in Figure 21 demonstrating the new definition of IVNGs.

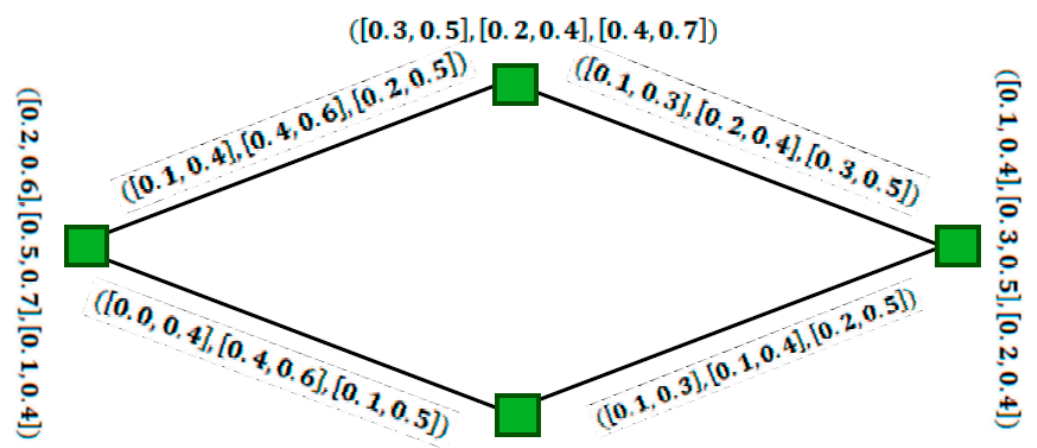

$([0.1,0.5],[0.2,0.4],[0.1,0.6])$

Figure 21. Interval-valued neutrosophic graph with undefined intervals.

Next, we discuss the existing definition for taking the complement of IVNG and show its limitations with the help of examples. Then, we propose a new definition for the complement of IVNG as the existing definition leads us to some undefined intervals.

Definition 17. [48] The complement of IVNG $G=(V, E)$ is defined by $G^{c}=\left(V^{c}, E^{c}\right)$ where $V^{c}=V$ and the membership, abstinence and non-membership grades of E satisfy

$$
\begin{aligned}
& \left(\hat{\mathrm{S}}^{L}\right)^{c}\left(v_{i}, v_{j}\right)=\min \left(S^{L}\left(v_{i}\right), S^{L}\left(v_{j}\right)\right)-\hat{\mathrm{S}}^{L}\left(\left(v_{i}, v_{j}\right)\right) \text {. } \\
& \left(\hat{\mathrm{S}}^{U}\right)^{c}\left(v_{i}, v_{j}\right)=\min \left(S^{U}\left(v_{i}\right), S^{U}\left(v_{j}\right)\right)-\hat{S}^{U}\left(v_{i}, v_{j}\right) \text {. } \\
& \left(\hat{\mathrm{I}}^{L}\right)^{c}\left(v_{i}, v_{j}\right)=\max \left(I^{L}\left(v_{i}\right), I^{L}\left(v_{j}\right)\right)-\hat{\mathrm{I}}^{L}\left(\left(v_{i}, v_{j}\right)\right) \text {. } \\
& \left(\hat{\mathrm{I}}^{U}\right)^{c}\left(v_{i}, v_{j}\right)=\max \left(I^{U}\left(v_{i}\right), I^{U}\left(v_{j}\right)\right)-\hat{\mathrm{I}}^{U}\left(v_{i}, v_{j}\right) \text {. } \\
& \left(Ð^{L}\right)^{c}\left(v_{i}, v_{j}\right)=\max \left(D^{L}\left(v_{i}\right), D^{L}\left(v_{j}\right)\right)-\bigoplus^{L}\left(\left(v_{i}, v_{j}\right)\right) \text {. } \\
& \left(\Xi^{U}\right)^{c}\left(v_{i}, v_{j}\right)=\max \left(D^{U}\left(v_{i}\right), D^{U}\left(v_{j}\right)\right)-Ð^{U}\left(v_{i}, v_{j}\right) \text {. }
\end{aligned}
$$

Example 15. The following IVNG depicted in Figure 22 shows that the Definition 17 for the complement of IVNG leads us to some undefined intervals.

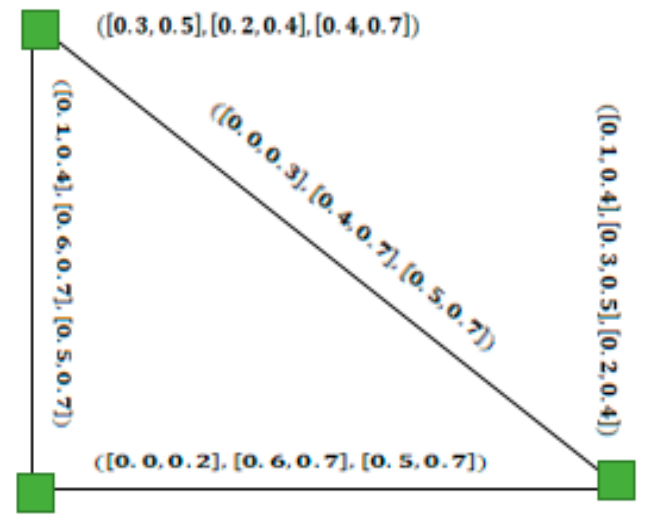

$([0.2,0.6],[0.5,0.7],[0.1,0.4])$

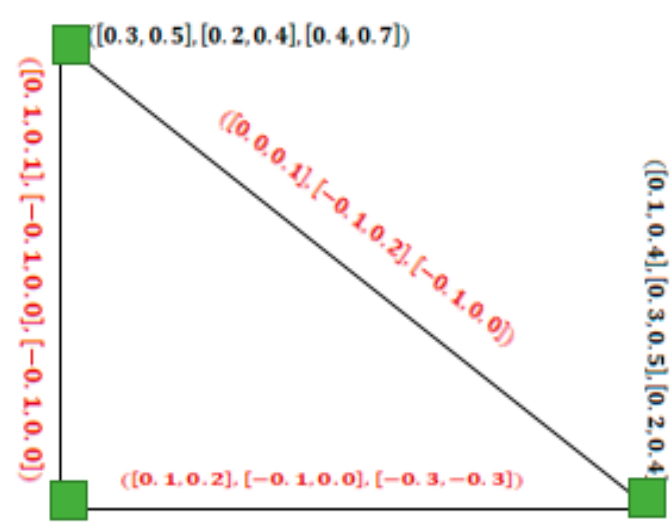

$([0.2,0.6],[0.5,0.7],[0.1,0.4])$

Figure 22. Complement of the Interval-valued neutrosophic graph by Definition 15. 
As the IVNG is a generalization of IVFG and IVIFG, its complement defined in [31] is not well-defined; therefore, we propose a new definition for the complement of IVNG as follows.

Definition 18. The complement of IVNG $G=(V, E)$ is defined by $G^{c}=\left(V^{c}, E^{c}\right)$ where $V^{c}=V$ and the membership, abstinence and non-membership grades of $E$ are satisfying the conditions:

$$
\begin{aligned}
& \left(\hat{\mathrm{S}}^{L}\right)^{c}\left(v_{i}, v_{j}\right)=\min \left(S^{L}\left(v_{i}\right), S^{L}\left(v_{j}\right)\right)-\hat{\mathrm{S}}^{L}\left(\left(v_{i}, v_{j}\right)\right) . \\
& \left(\hat{\mathrm{S}}^{U}\right)^{c}\left(v_{i}, v_{j}\right)=\min \left(S^{U}\left(v_{i}\right), S^{U}\left(v_{j}\right)\right)-\hat{\mathrm{S}}^{U}\left(v_{i}, v_{j}\right)+\min \left(S^{L}\left(v_{i}\right), S^{L}\left(v_{j}\right)\right) \text {. } \\
& \left(\hat{\mathrm{I}}^{L}\right)^{c}\left(v_{i}, v_{j}\right)=\max \left(I^{L}\left(v_{i}\right), I^{L}\left(v_{j}\right)\right)-\hat{\mathrm{I}}^{L}\left(\left(v_{i}, v_{j}\right)\right) . \\
& \left(\hat{\mathrm{I}}^{U}\right)^{c}\left(v_{i}, v_{j}\right)=\max \left(I^{U}\left(v_{i}\right), I^{U}\left(v_{j}\right)\right)-\hat{\mathrm{I}}^{U}\left(v_{i}, v_{j}\right)+\max \left(I^{L}\left(v_{i}\right), I^{L}\left(v_{j}\right)\right) \text {. }
\end{aligned}
$$

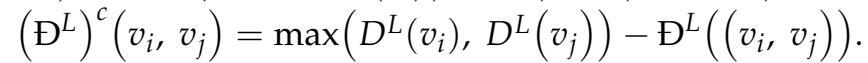

$$
\begin{aligned}
& \left(\Xi^{U}\right)^{c}\left(v_{i}, v_{j}\right)=\max \left(D^{U}\left(v_{i}\right), D^{U}\left(v_{j}\right)\right)-\Xi^{U}\left(v_{i}, v_{j}\right)+\max \left(D^{L}\left(v_{i}\right), D^{L}\left(v_{j}\right)\right) \text {. }
\end{aligned}
$$

Example 16. Consider the following IVNGs shown in Figure 23 and its complement graph is depicted in Figure 24. Through some easy calculation, one can easily verify that $\left(G^{c}\right)^{c}=G$.

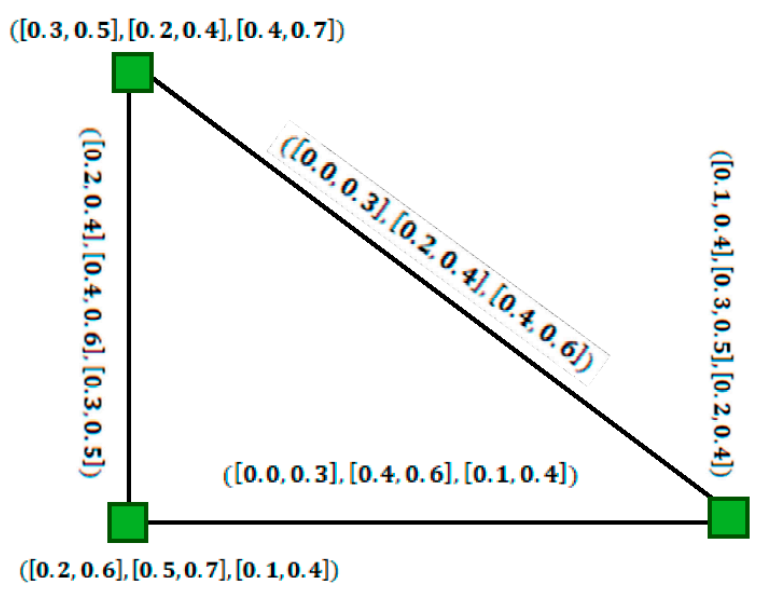

Figure 23. Interval-valued neutrosophic graph.

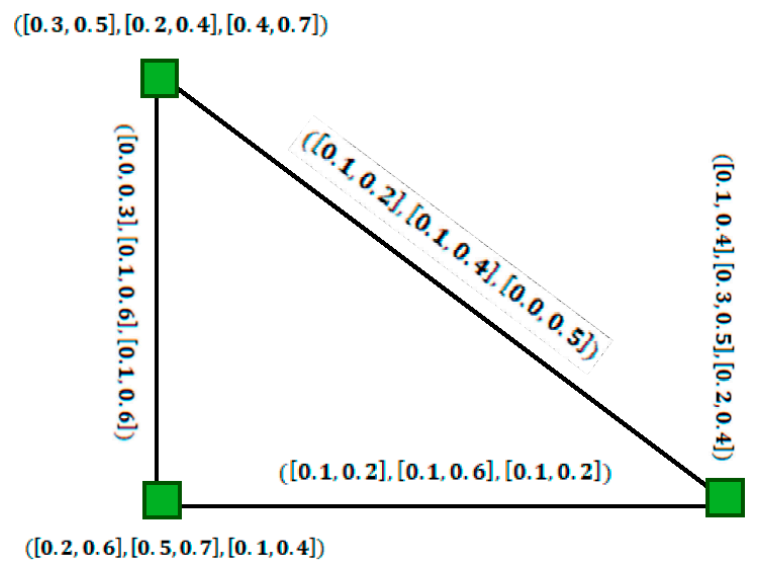

Figure 24. Complement of the graph depicted in Figure 23.

So far in our study, we have developed the theory of IVFGs and its generalizations, providing examples that explained the limitations in the existing definitions and the fitness of the new definitions. 
Remark 1. The work proposed is applicable whether the graphs are directed or undirected.

Now, a real-life application is presented to show the feasibility of the proposed work. The process of ranking universities is explained based on SVNGs.

\section{Illustrative Example}

The higher education commission (HEC) of Pakistan needed to evaluate the Pakistani universities from research perspectives. HEC Pakistan planned to give away some financial support to those universities whose research was comparatively better. A university with a good research score will earn greater financial support. Here, we shall discuss the case of the federal capital Islamabad. Four universities, $z_{1}, z_{2}, z_{3}$ and $z_{4}$, from Islamabad are chosen, representing Quaid e Azam university, National University of Science and Technology, Comsats university and International Islamic University Islamabad. The criterion for the ranking of universities is "research productivity". The members of the quality assurance cell (QEC) of HEC provide their information in the form of single-valued neutrosophic preference relations (SVNPRs) as given in Figure 25. The weight vector corresponding to the them is given by $w=(0.3,0.2,0.3,0.2)^{T}$. The detailed steps of algorithm for this process are explained followed by stepwise calculations of this problem.

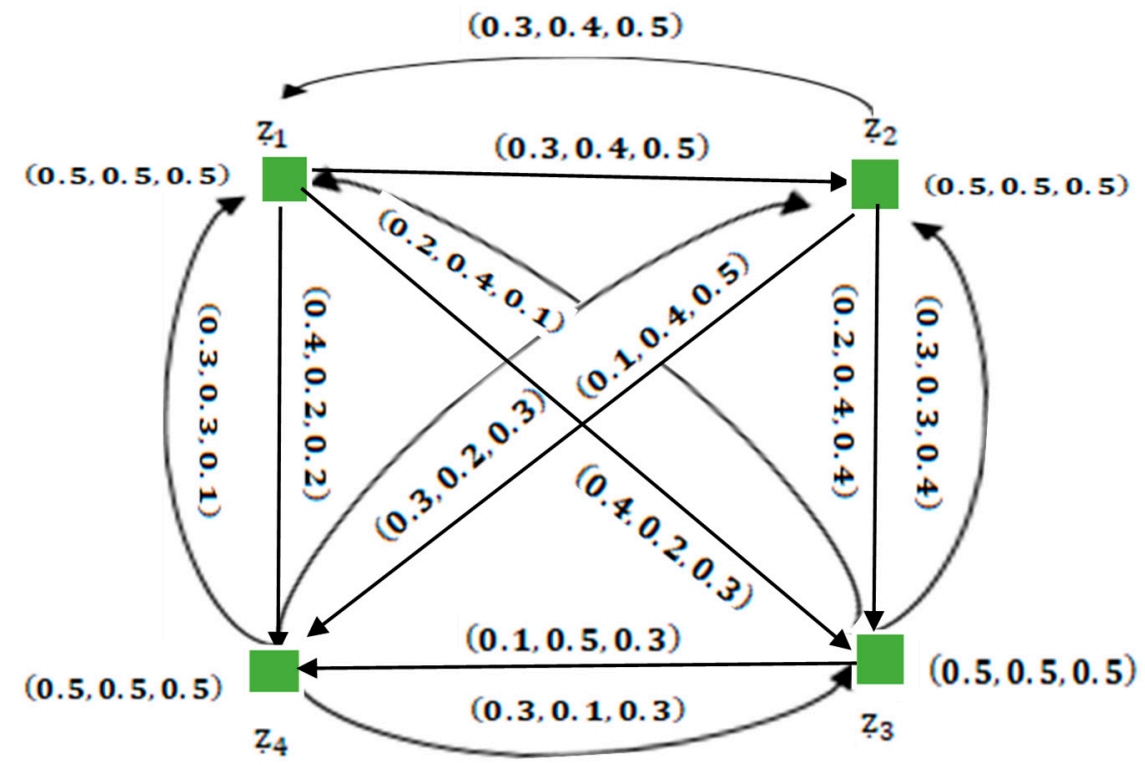

Figure 25. Directed network with single-valued neutrosophic information.

Steps of the algorithm:

Step 1: Establishing SVNPRs: This step involves the evaluation of objects by decision-makers in the form of SVNGs;

Step 2: The SVNPRs form a relational matrix known as the single-valued neutrosophic relational matrix (SVNRM) denoted by $\dot{R} M=\left(m \dot{r}_{i j}\right)_{n \times n}$ where $\dot{R} m_{i j}=\left(S_{i j}, I_{i j}, D_{i j}\right)$ such that $\dot{R} 0 \leq$ $S_{i j}, I_{i j}, D_{i j} \leq 1$ and $\dot{R} S_{i j}+I_{i j}+D_{i j} \leq 3$;

Step 3: Aggregating the different preferences by using the weighted averaging aggregation operator named as single-valued neutrosophic weighted averaging (SVNWA) operators [8] as follows:

$$
m \dot{r}_{i}=S V N W A\left(m \dot{r}_{i 1}, m \dot{r}_{i 2}, \ldots, m \dot{r}_{i n}\right)=\left(1-\prod_{j=1}^{n}\left(1-S_{i j}\right)^{w_{j}},\left(\prod_{j=1}^{n} I_{i j}\right)^{w_{j}},\left(\prod_{j=1}^{n} D_{i j}\right)^{w_{j}}\right)
$$


where $w_{j}$ is the weight vector for each preference such that $w_{j}>0$ and $\sum_{j=1}^{n} w_{j}=1$;

Step 4: Computing the score value of the aggregated number $m_{i}=\left(S_{i}, I_{i}, D_{i}\right)(i=1,2, \ldots, n)$ by using the score function

$$
S\left(m_{i}\right)=\frac{S_{i}+1-I_{i}+1-D_{i}}{3} ;
$$

Step 5: Ranking all the alternatives based on the descending order of the score values.

Now, by applying the above-mentioned steps to the considered data, we summarized their computational steps as below:

Step 1: The information from QEC of HEC Pakistan related to each university is taken in the form of SVNGs and summarized in Figure 25.

Here, the importance of a new definition of an SVNG is clear. In decision-making problems, we usually have two types of attributes, known as attributes of cost type and of benefit types. In the case that the attributes are of cost types, the data is normalized using the definition of complement of SVNGs. Therefore, if we utilize the existing definition of SVNGs and their complement as we have done in Example 11, we obtain some undefined results. The case is similar with other structures. All this shows the importance of the new proposed definitions of several fuzzy graphs and their complements.

Step 2: From the SVNPRs provided in Figure 25, we have the following relational matrix.

$$
M \dot{R}=\left(m \dot{r}_{i j}\right)_{4 \times 4}=\left(\begin{array}{llll}
(0.5,0.5,0.5) & (0.3,0.4,0.5) & (0.4,0.2,0.3) & (0.4,0.2,0.2) \\
(0.3,0.4,0.5) & (0.5,0.5,0.5) & (0.2,0.4,0.4) & (0.1,0.4,0.5) \\
(0.2,0.4,0.1) & (0.3,0.3,0.4) & (0.5,0.5,0.5) & (0.1,0.5,0.3) \\
(0.3,0.3,0.1) & (0.3,0.2,0.3) & (0.3,0.1,0.3) & (0.5,0.5,0.5)
\end{array}\right)
$$

Step 3: Using single-valued neutrosophic weighted averaging operators on the relational matrix to aggregate the data,

$$
m \dot{r}_{i}=\operatorname{SVNWA}\left(m \dot{r}_{i 1}, m \dot{r}_{i 2}, \ldots, m \dot{r}_{i n}\right)=\left(1-\prod_{j=1}^{n}\left(1-S_{i j}\right)^{w_{j}},\left(\prod_{j=1}^{n} I_{i j}\right)^{w_{j}},\left(\prod_{j=1}^{n} D_{i j}\right)^{w_{j}}\right)
$$

and the aggregated values are obtained as

$$
\begin{aligned}
& m \dot{r}_{1}=(0.414150269,0.3024252,0.3571309) ; \\
& \dot{r} m_{2}=(0.283693469,0.4182558,0.4676242) ; \\
& \dot{r} m_{3}=(0.307394227,0.4222088,0.2663957) ; \\
& \dot{r} m_{4}=(0.345556087,0.2203618,0.2389762) .
\end{aligned}
$$

Step 4: The score values of the aggregated data are obtained as

$$
S\left(m_{1}\right)=0.584864723, \underline{s} S\left(m \dot{r}_{2}\right)=0.465937823, S s\left(m \dot{r}_{3}\right)=0.539596576, s \underline{S} S\left(m \dot{r}_{4}\right)=0.62873936
$$

Step 5: Since $S\left(m_{4}\right)>S\left(m_{1}\right)>S\left(m_{3}\right)>S\left(m_{2}\right)$, we obtained the ranking order of the given universities as $z_{4} \succ z_{1} \succ z_{3} \succ z_{2}$, where $\succ$ refers to "preferred to". Thus, the ranking results indicate that International Islamic University Islamabad performs best in research productivity among the four universities of federal capital of Islamabad in the evaluation of the quality assurance cell of HEC. 


\section{Conclusions}

In this manuscript, we successfully pointed out the shortcomings in the current definitions of IVFG, IVIFG with the help of examples and developed a new improved definition for these concepts. It is also discussed that the current definitions of complements for IVFG and IVIFG lead us to some undefined results; therefore, some new definitions for complements of IVFG and IVIFG are proposed and supported by examples. Further, it is observed that the definition of SVNG has some serious flaws, described by examples. Thus, a new modified definition for SVNG has been developed and supported by some examples. The concept of IVNG is also modified, and the validity of the modified definition is tested with examples. Throughout this article, we defined all those terms which were not previously defined well. In the near future, we shall investigate some other results of IVFGs, IVIFG, IVNG, SVNGs and extend them to solve decision-making problems under fuzzy or uncertain environments [52-58].

Author Contributions: Conceptualization, N,J; K.U; and T.M; ; Methodology, N,J; K.U; T.M. and B.D.; Validation, N.J.; K.U.; T.M.; H.G.; and A.B.S; Formal Analysis, N.J.; K.U.; T.M.; A.B.S; and S.B.; Investigation, N.J.; K.U.; T.M.; B.D..; Writing-Original Draft Preparation, N.J.; K.U.; T.M.; H.G..; Writing-Review \& Editing, N.J.; K.U.; T.M.; H.G.; Visualization, N.J.; K.U.; T.M.; H.G.; S.B.

Funding: This research received no external funding.

Acknowledgments: The authors are thankful to the editor and anonymous reviewers for their useful suggestions regarding the improvement of this manuscript.

Conflicts of Interest: The authors declare no conflict of interest.

\section{References}

1. Zadeh, L.A. Fuzzy sets. Inf. Control 1965, 8, 338-353. [CrossRef]

2. Gorzalczany, M.B. A method of inference in approximate reasoning based on interval—Valued fuzzy sets. Fuzzy Sets Syst. 1987, 21, 1-17. [CrossRef]

3. Atanassov, K.T. Intuitionistic fuzzy sets. Fuzzy Sets Syst. 1986, 20, 87-96. [CrossRef]

4. Atanassov, K.; Gargov, G. Interval-valued intuitionistic fuzzy sets. Fuzzy Sets Syst. 1989, 31, $343-349$. [CrossRef]

5. Smarandache, F. Neutrosophy. Neutrosophic Probability, Set, and Logic, ProQuest Information E Learning; American Research Press Rehoboth: Ann Arbor, MI, USA, 1998.

6. Wang, H.; Smarandache, F.; Zhang, Y.Q.; Sunderraman, R. Single valued neutrosophic sets. Multisp. Multistruct. 2010, 4, 410-413.

7. Wang, H.; Smarandache, F.; Zhang, Y.Q.; Smarandache, R. Interval Neutrosophic Sets and Logic: Theory and Applications in Computing; Hexis: Phoenix, AZ, USA, 2005.

8. Peng, J.J.; Wang, J.Q.; Wang, J.; Zhang, H.Y.; Chen, Z.H. Simplified neutrosophic sets and their applications in multi-criteria group decision-making problems. Int. J. Syst. Sci. 2016, 47, 2342-2358. [CrossRef]

9. Garg, H. New exponential operational laws and their aggregation operators for interval-valued Pythagorean fuzzy multicriteria decision-Making. Int. J. Intell. Syst. 2018, 33, 653-683. [CrossRef]

10. Peng, J.J.; Wang, J.Q.; Zhang, H.Y.; Chen, X.H. An outranking approach for multi-criteria decision-making problems with simplified neutrosophic sets. Appl. Soft Comput. 2014, 25, 336-346. [CrossRef]

11. Garg, H. Some robust improved geometric aggregation operators under interval-valued intuitionistic fuzzy environment for multi-criteria decision-making process. J. Ind. Manag. Optim. 2018, 14, 283-308. [CrossRef]

12. Garg, H. Novel intuitionistic fuzzy decision making method based on an improved operation laws and its application. Eng. Appl. Artif. Intell. 2017, 60, 164-174. [CrossRef]

13. Peng, X.; Dai, J. Algorithms for interval neutrosophic multiple attribute decision-making based on MABAC, similarity measure, and EDAS. Int. J. Uncertain. Quantif. 2017, 7, 395-421. [CrossRef]

14. Peng, X.D.; Dai, J.G. Approaches to single-valued neutrosophic madm based on mabac, topsis and new similarity measure with score function. Neural Comput. Appl. 2018, 29, 939-954. [CrossRef]

15. Garg, H. Some picture fuzzy aggregation operators and their applications to multicriteria decision-making. Arab. J. Sci. Eng. 2017, 42, 5275-5290. [CrossRef] 
16. Garg, H.; Kumar, K. A novel exponential distance and its based TOPSIS method for interval-valued intuitionistic fuzzy sets using connection number of SPA theory. Artif. Intell. Rev. 2018, 1-30. [CrossRef]

17. Smarandache, F. Subtraction and division of neutrosophic numbers. Crit. Rev. 2016, 13, 103-110.

18. Xu, Z.S. Intuitionistic fuzzy aggregation operators. IEEE Trans. Fuzzy Syst. 2007, 15, 1179-1187.

19. Garg, H.; Arora, R. Generalized intuitionistic fuzzy soft power aggregation operator based on t-norm and their application in multi criteria decision-making. Int. J. Intell. Syst. 2019, 34, 215-246. [CrossRef]

20. Garg, H.; Kumar, K. Distance measures for connection number sets based on set pair analysis and its applications to decision making process. Appl. Intell. 2018, 48, 3346-3359. [CrossRef]

21. Garg, H.; Nancy. Non-linear programming method for multi-criteria decision making problems under interval neutrosophic set environment. Appl. Intell. 2018, 48, 2199-2213. [CrossRef]

22. Wei, G.; Zhao, X. An approach to multiple attribute decision making with combined weight information in interval-valued intuitionistic fuzzy environmental. Control Cybern. 2012, 41, 97-112.

23. Wei, G.W. Picture 2-tuple linguistic bonferroni mean operators and their application to multiple attribute decision making. Int. J. Fuzzy Syst. 2017, 19, 997-1010. [CrossRef]

24. Garg, H.; Nancy. Some hybrid weighted aggregation operators under neutrosophic set environment and their applications to multicriteria decision-making. Appl. Intell. 2018, 48, 4871-4888. [CrossRef]

25. Garg, H.; Nancy. New logarithmic operational laws and their applications to multiattribute decision making for single-valued neutrosophic numbers. Cogn. Syst. Res. 2018, 52, 931-946. [CrossRef]

26. Kaufmann, A. Introduction to Fuzzy Subsets; Academic Press: New York, NY, USA, 1975; Volume 1.

27. Zadeh, L.A.; Fu, K.S.; Tanaka, K. (Eds.) Fuzzy sets and their applications to cognitive and decision processes. In Proceedings of the US-Japan Seminar on Fuzzy Sets and Their Applications, Berkeley, CA, USA, 1-4 July 1974.

28. Akram, M.; Dudek, W.A. Interval-valued fuzzy graphs. Comput. Math. Appl. 2011, 61, 289-299. [CrossRef]

29. Bhattacharya, P. Some remarks on fuzzy graphs. Pattern Recognit. Lett. 1987, 6, 297-302. [CrossRef]

30. Bhutani, K.R. On automorphisms of fuzzy graphs. Pattern Recognit. Lett. 1989, 9, 159-162. [CrossRef]

31. Bhutani, K.R.; Rosenfeld, A. Strong arcs in fuzzy graphs. Inf. Sci. 2003, 152, 319-322. [CrossRef]

32. Mordeson, J.N.; Chang-Shyh, P. Operations on fuzzy graphs. Inf. Sci. 1994, 79, 159-170. [CrossRef]

33. Rashmanlou, H.; Jun, Y.B. Complete interval-valued fuzzy graphs. Ann. Fuzzy Math. Inform. 2013, 6, 677-687.

34. Pal, M.; Rashmanlou, H. Irregular interval valued fuzzy graphs. arXiv, 2014; arXiv:1407.6190.

35. Akram, M. Interval-valued fuzzy line graphs. Neural Comput. Appl. 2012, 21, 145-150. [CrossRef]

36. Rashmanlou, H.; Pal, M. Balanced interval-valued fuzzy graphs. J. Phys. Sci. 2013, 17, 43-57.

37. Pramanik, T.; Samanta, S.; Pal, M. Interval-valued fuzzy planar graphs. Int. J. Mach. Learn. Cybern. 2016, 7, 653-664. [CrossRef]

38. Talebi, A.; Rashmanlou, H. Isomorphism on interval-valued fuzzy graphs. Ann. Fuzzy Math. Inform. 2013, 6, 47-58.

39. Parvathi, R.; Karunambigai, M. Intuitionistic fuzzy graphs. In Computational Intelligence, Theory and Applications; Springer: New York, NY, USA, 2006; pp. 139-150.

40. Mishra, S.; Pal, A. Product of interval valued intuitionistic fuzzy graph. Ann. Pure Appl. Math. 2013, 5, 37-46.

41. Mishra, S.; Pal, A. Regular interval-valued intuitionistic fuzzy graphs. J. Inform. Math. Sci. 2017, 9, 609-621.

42. Ismayil, A.M.; Ali, A.M. On strong interval-valued intuitionistic fuzzy graph. Int. J. Fuzzy Math. Syst. 2014, 4, 161-168.

43. Broumi, S.; Talea, M.; Bakali, A.; Smarandache, F. Single valued neutrosophic graphs. Florentin Smarandache Surapati Pramanik 2015, 187.

44. Broumi, S.; Talea, M.; Bakali, A.; Smarandache, F.; Kumar, P.K. Shortest path problem on single valued neutrosophic graphs. In Proceedings of the 2017 International Symposium on Networks, Computers and Communications (ISNCC), Marrakech, Morocco, 16-18 May 2017; pp. 1-6.

45. Broumi, S.; Bakal, A.; Talea, M.; Smarandache, F.; Vladareanu, L. Applying dijkstra algorithm for solving neutrosophic shortest path problem. In Proceedings of the 2016 International Conference on Advanced Mechatronic Systems (ICAMechS), Melbourne, VIC, Australia, 30 November-3 December 2016; pp. 412-416.

46. Broumi, S.; Ullah, K.; Bakali, A.; Talea, M.; Singh, P.K.; Mahmood, T.; Smarandache, F.; Bahnasse, A.; Patro, S.K.; Oliveira, A. Novel System and Method for Telephone Network Planing Based on Neutrosophic Graph. Glob. J. Comput. Sci. Technol. 2018, 18, 1-10.

47. Akram, M.; Shahzadi, S. Neutrosophic soft graphs with application. J. Intell. Fuzzy Syst. 2017, 32, 841-858. [CrossRef] 
48. Broumi, S.; Talea, M.; Bakali, A.; Smarandache, F. Interval valued neutrosophic graphs. Crit. Rev. XII 2016, 2016, 5-33.

49. Akram, M.; Nasir, M. Concepts of Interval-Valued Neutrosophic Graphs. Infin. Study 2017, 6, $22-41$. [CrossRef]

50. Broumi, S.; Smarandache, F.; Talea, M.; Bakali, A. Operations on Interval Valued Neutrosophic Graphs; Florentin Smarandache Surapati Pramanik. Infin. Study 2016.

51. Broumi, S.; Talea, M.; Bakali, A.; Smarandache, F. On strong interval valued neutrosophic graphs. Crit. Rev. 2016, 12, 49-71.

52. Garg, H.; Arora, R. Dual hesitant fuzzy soft aggregation operators and their application in decision making. Cogn. Comput. 2018, 10, 769-789. [CrossRef]

53. Garg, H.; Rani, D. Some generalized complex intuitionistic fuzzy aggregation operators and their application to multicriteria decision-making process. Arab. J. Sci. Eng. 2018, 10, 769-789. [CrossRef]

54. Rani, D.; Garg, H. Complex intuitionistic fuzzy power aggregation operators and their applications in multi-criteria decision-making. Expert Syst. 2018, 35, e12325. [CrossRef]

55. Kaur, G.; Garg, H. Multi-Attribute decision-Making based on bonferroni mean operators under cubic intuitionistic fuzzy set environment. Entropy 2018, 20, 65. [CrossRef]

56. Garg, H.; Nancy. Multi-criteria decision-making method based on prioritized muirhead mean aggregation operator under neutrosophic set environment. Symmetry 2018, 10, 280. [CrossRef]

57. Wei, G.; Garg, H.; Gao, H.; Wei, C. Interval-Valued Pythagorean Fuzzy Maclaurin Symmetric Mean Operators in Multiple Attribute Decision Making. IEEE Access 2018, 6, 67866-67884. [CrossRef]

58. Garg, H. Hesitant Pythagorean fuzzy Maclaurin symmetric mean operators and its applications to multiattribute decision making process. Int. J. Intell. Syst. 2018. [CrossRef]

(C) 2019 by the authors. Licensee MDPI, Basel, Switzerland. This article is an open access article distributed under the terms and conditions of the Creative Commons Attribution (CC BY) license (http:/ / creativecommons.org/licenses/by/4.0/). 